\title{
Relationship Between Structure and Properties of the Large-Size Billet of Titanium Alloy PT-7M
}

\section{F. V. Vodolazskiy', S. M. Illarionova1, N. A. Barannikova1', Ya. I. Kosmatskiy², E. A. Gornostaeva ${ }^{2}$, and A. G. Illarionov ${ }^{1}$ \\ ${ }^{1}$ Ural Federal University, 19, Mira str., Ekaterinburg, Russian Federation \\ 2 JSC RosNITI, 30, Novorossiiskay street, Chelyabinsk, Russia}

\section{Abstract}

In this paper the interrelation between the structure, hardness and strain resistance at $875{ }^{\circ} \mathrm{C}$ of the hot-forged pipe billet of the titanium alloy PT-7M (Ti-2.2Al-2.5Zr) was studied by the methods of macro, micro, XRDA, durometric analyzes and hot upsetting operation at $875^{\circ} \mathrm{C}$. It was found, that the volume fraction of the large grains reduced and recrystallized from the center to the surface of the pipe billet. As a result, hardness and strain resistance grew at $875^{\circ} \mathrm{C}$ from the center to the surface of the billet.

Corresponding Author:

F. V. Vodolazskiy

f.v.vodolazskiy@urfu.ru

Received: 25 February 2019

Accepted: 9 April 2019

Published: 15 April 2019

Publishing services provided by

Knowledge E

(c) F. V. Vodolazskiy et al. This article is distributed under the terms of the Creative Commons Attribution License, which permits unrestricted use and redistribution provided that the original author and source are credited.

Selection and Peer-review under the responsibility of The Ural school-seminar of metal scientists-young researchers Conference Committee.
Keywords: titanium alloy PT-7M, hot deformation, phase composition, structure, texture, hardness, strain resistance.

\section{Introduction}

PT-7M (Ti-2.2Al-2.5Zr wt.\%) refers to the wrought $\alpha$-alloys [1]. There is $100 \% \alpha$-phase (HCP lattice modification of titanium) under normal conditions. PT-7M alloy is characterized by high casting properties, strength, heat resistance, thermal stability, and low tendency to the cold brittleness in comparison with pure titanium, due to the aluminum and zirconium alloying [1, 2]. It has high corrosion resistance in sea water, it is well deformed in hot and cold conditions and is welded by all types of welding. PT-7M alloy is mainly used for the production of corrosion resistant pipes at room and elevated (up to $400-450^{\circ} \mathrm{C}$ ) temperatures [2-4].

Large-sized hot-forged billets with a diameter of more than $150 \mathrm{~mm}$ are usually taken as the initial semi-finished product for pipe production from titanium alloys, including PT-7M.

Research about other titanium alloys [5] shows that billets may have inhomogeneity of structure and properties through the section. The reason of such inhomogeneity 
is transient conditions of deformation and the complex structure of the source casting accordingly. Such inhomogeneity may affects further on the distribution of efforts through the section of the billet during hot deformation as received a pipe semi-finished product. Studies about alloy PT-7M in this direction could not be found. Consequently, the research studied the interrelation between structure and properties through the section of the large-size billet of titanium alloy PT-7M.

\section{Research Material and Methods}

The material for the study was hot-forged billet $(\varnothing 188 \mathrm{~mm})$ of PT-7M alloy (Ti-2.2Al-2.7Z wt.\%) according GOST 19807-91 [7]. The temperature of the polymorphic transformation $\left(\mathrm{T}_{p t}\right)$ is $945^{\circ} \mathrm{C}$. Templates were cut along the radius of hot-rolled billet of PT-7M alloy.

Macro-, microstructural and hardness analyzes as well as hot upset forging were used as research methods. Macrostructure analysis - using the scale method [5], microstructural - using an Olympus GX51 microscope, X-ray difraction analysis (XRDA) - using a Bruker D8 Advance diffractometer ( $\mathrm{Cu} \mathrm{K}_{\alpha}$-radiation). Measurement of Vickers hardness was carry out at the load of $100 \mathrm{~kg}$ on a Zwick / Roell ZHU type 6187-5 LKV universal hardness tester with a load of $100 \mathrm{~kg}(980.7 \mathrm{~N})$ along three radius at a distance of $5 \mathrm{~mm}$. The structure analysis was performed on the transverse and longitudinal sections of the templates after the etching in a $15 \%$ solution of hydrofluoric acid (for macrostructure) and after etching in aqueous solution of nitric and hydrofluoric acids in a ratio of 1 part HF + 3 parts $\mathrm{HNO} 3+5$ parts $\mathrm{H} 2 \mathrm{O}$ (for microstructure).

\section{Results and Discussion}

The macrostructure of templates of cross-section and longitudinal section of hot-rolled billet is shown in Fig.1. The macrostructure of transverse section is generally characterized by a 3-4th grain size number (grain size $\sim 1 \mathrm{~mm}$ ), according to the scale of macrostructures of titanium alloys [8]. There is some areas especially closer to the center of the billet where grain size is higher and can reach 7-8th grain size number (grain size $\sim 4-5 \mathrm{~mm}$ ), (Fig. 1, a). In the longitudinal section (Fig. 1, b) the macrostructure is characterized by a 1-2 number, according to the macrostructure inequality scale of titanium alloys [5]. This means that the ratio between grain size along the billet axis and across the billet axis is about 2. An analysis of the macrostructure is shown there is an inhomogeneity through the section of the hot-forged billet and it is characterized by the presents of large grains. Their quantity is higher in the central area of the billet and lower in the near 
surface area. The last, obviously, is associated with the cooling of the surface during deformation which is typical for titanium alloys [5].

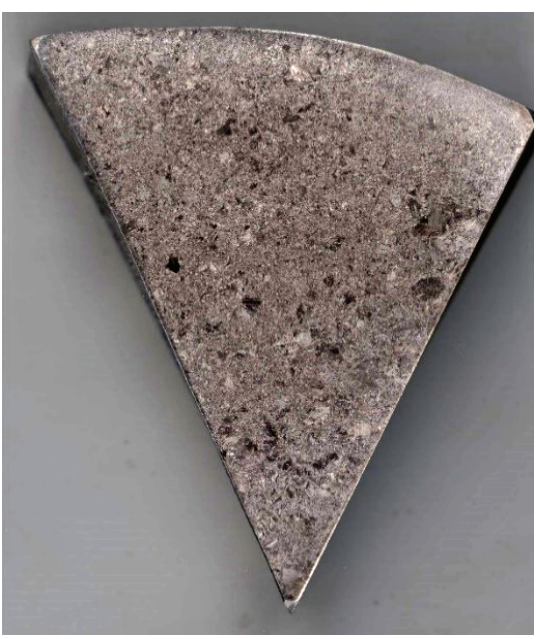

$a$

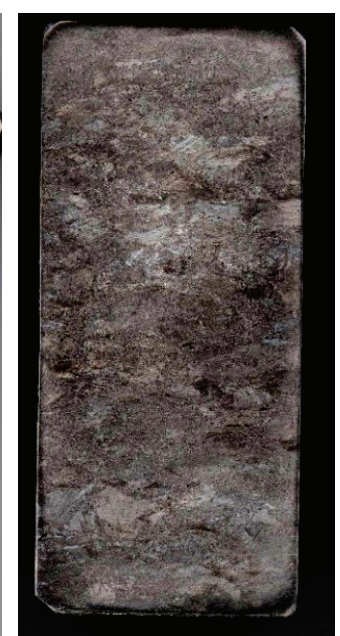

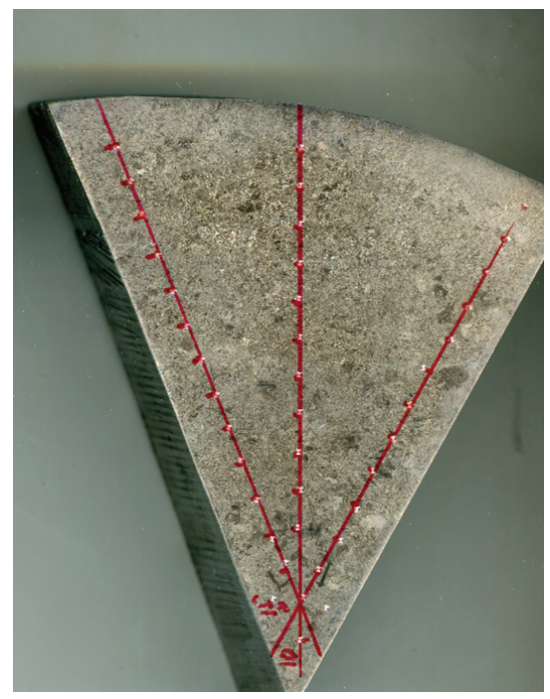

$c$

Figure 1: Macrostructure of the PT-7M alloy template after hot-forging in the transverse $(a)$, longitudinal section (b), and Vickers hardness (c) (without magnification).

The microstructure of the PT-7M alloy of the longitudinal and cross-section in different areas (center, $1 / 2$ radius, near surface) is shown in Fig. 2. Analysis (Fig. 2) is shown that the microstructure slightly changes across the sections. The quantity of equiaxial recrystallized grains (grain size up to 100 microns) is higher in the center of the billet and lower in the near surface area. In contrast, main part of deformed elongated grains are in the central area of the billet and only few of them near the surface (Fig. 2, a, c, e). It was also noted in the analysis of the macrostructure (Fig. 1, b).

The intragranular structure is look like a package of partially curved $\alpha$-plates (Fig. 2). Such structure is usually formed after the end of the forging at the temperature below the polymorphic $\alpha+\beta \rightarrow \beta$-transformation $\left(\mathrm{T}_{p t}\right)$. In our case, fragmentation of the $\alpha$-plates formed during the forging below $T_{p t}$ practically wasn't observed. Hence the degree of deformation and overcooling below $\mathrm{T}_{p t}$ during forging were not significant.

The X-rays diffraction scans presented on Fig. 3. There are only lines of $\alpha$-solid solution on the diffractograms, which is normal for $\alpha$-alloys, because they don't contain $\beta$ stabilizers. The average lattice parameters of the $\alpha$-phase of different sections of the billet are $a=0.29466 \mathrm{~nm}, c=0.46868 \mathrm{~nm}, c / a=1.5905$. The obtained values «c/a» parameter of the $\alpha$-phase are higher than of pure titanium (1.5873), which is typical for alloys with aluminum [9]. It should be noted the line $(002)_{\alpha}$ has maximum intensity on diffractograms of longitudinal section (Fig. 3). In the transverse direction, the basal plane $(002)_{\alpha}$ is practically absent, and the line $(100)_{\alpha}$ intensity is higher. This fact indicates that 
there is a presence of preferential orientations in the $\alpha$-phase, the tangential texture $\{0001\}<1-100>$ when the normal to the basal plane is perpendicular to the axis of the billet. This is typical for the process of $\alpha$-phase deformation [10].

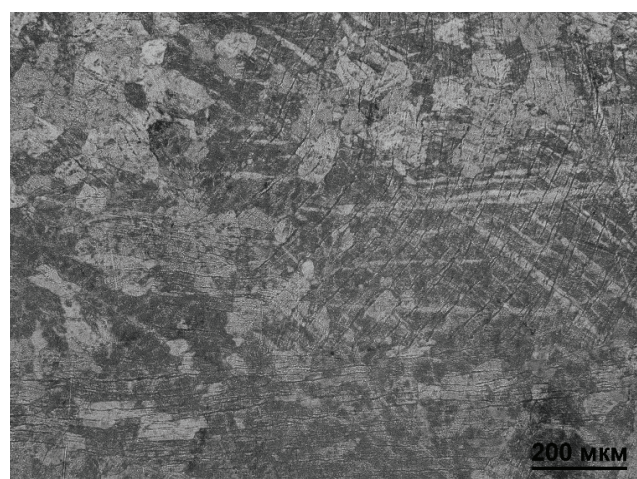

$a$

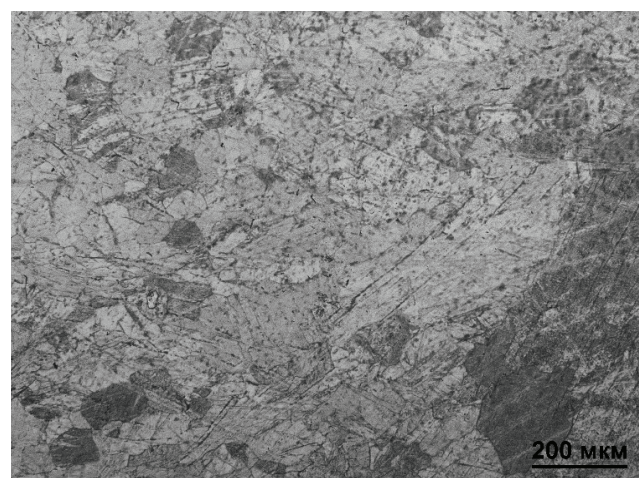

$c$

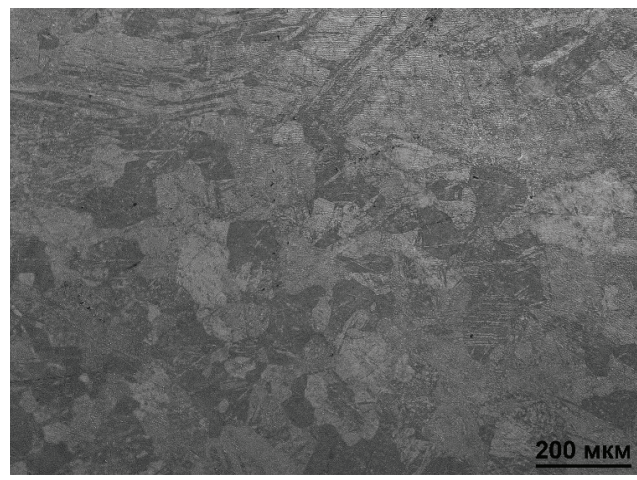

$e$

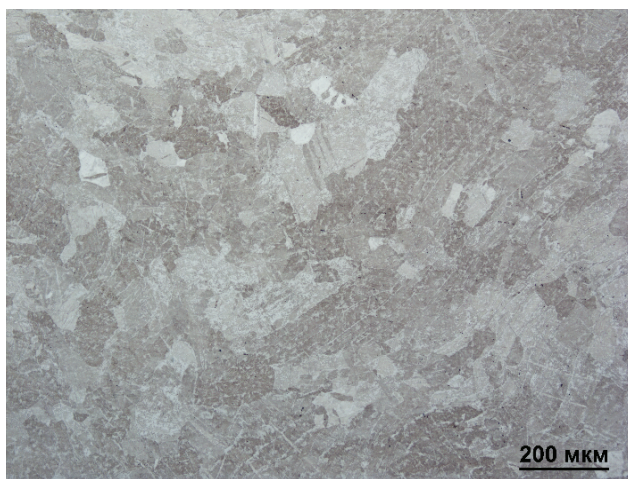

$b$

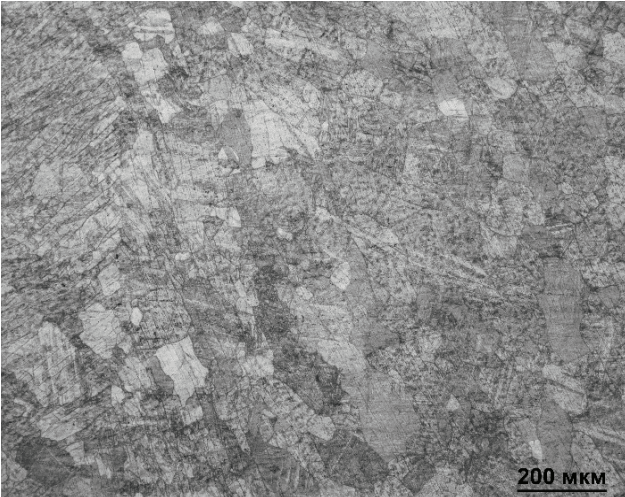

$d$

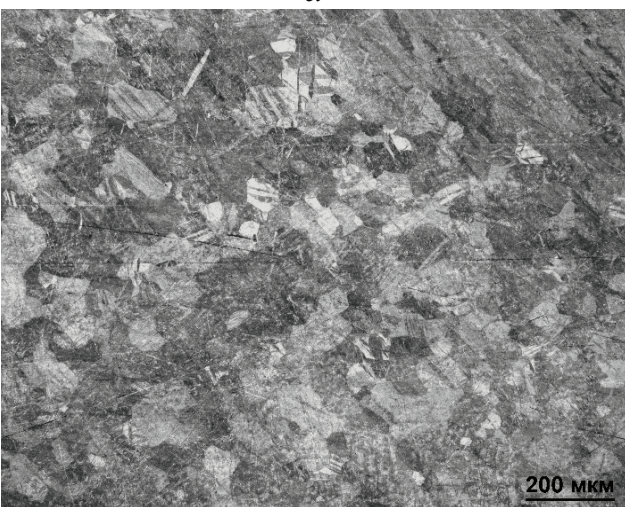

$f$

Figure 2: Microstructure of the alloy PT-7M in the longitudinal $(a, c, e)$ and transverse $(b, d, f)$ section from different areas of the billet: $a, b$ - near the center; $c, d$-near $1 / 2$ radius; $e, f$ - near the surface.

Measurement of Vickers hardness presents on the Fig. 4. The measurement scheme is shown in Fig. 1, c. In general, the values of hardness over the cross section of the billet varies from $190 \mathrm{HV}$ to $225 \mathrm{HV}$, while the average and median values are close and equal to $207 \mathrm{HV}$. Linear approximation (Fig. 4) shows a trend of increment of hardness from the center of the templet to its surface. Obviously this is due to a decrease quantity of recrystallized grains and an increase in deformed grains in the structure (Fig. 2). It 


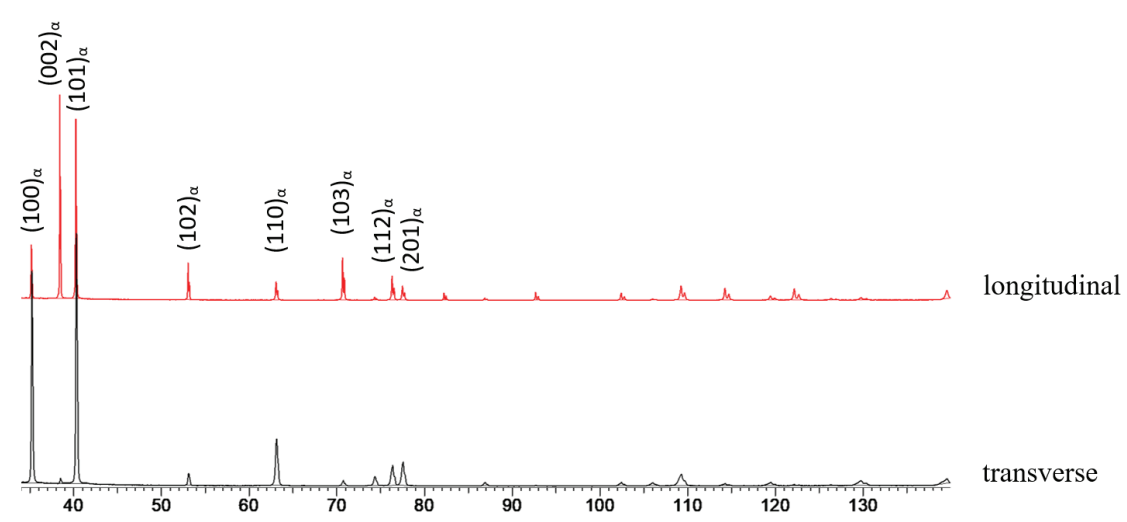

(a)

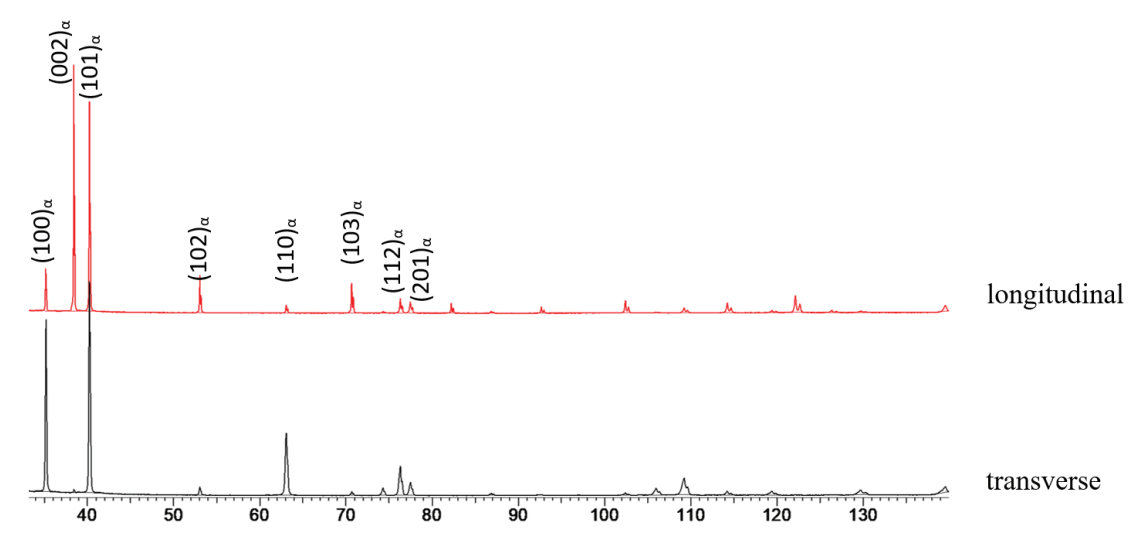

(b)

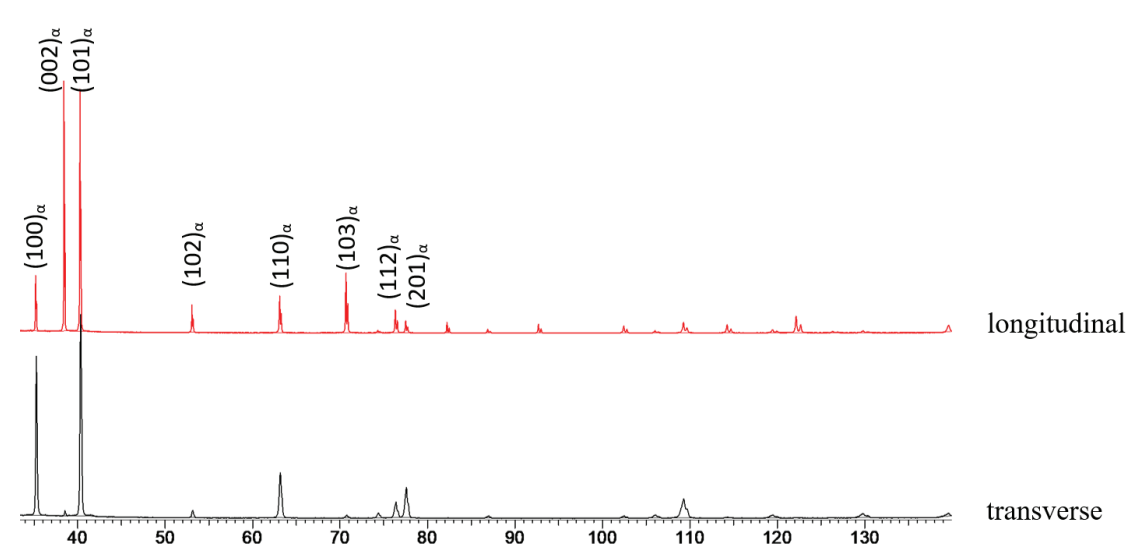

(c)

Figure 3: Diffractograms with longitudinal and cross-section from different areas of the billet: $a$ - near the center; $b$ - by $1 / 2$ radius; $c$ - near the surface.

is known [11] that, the dislocation density is significantly reduced over the recrystallized state compared with the deformed state, which decrease strength properties, including hardness.

To evaluate the homogeneity of the strength properties over the cross section of a hot-forged billet at elevated temperatures, the compression tests were carried out on 


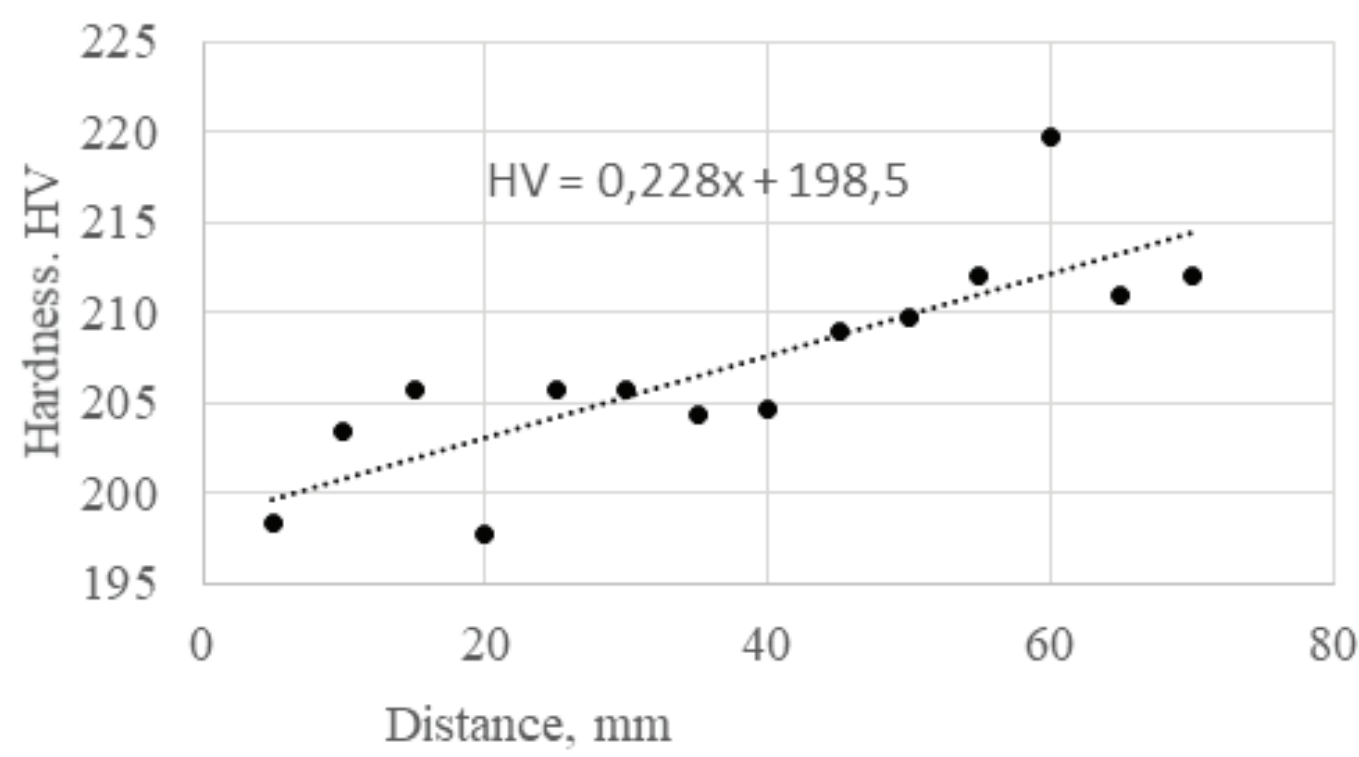

Figure 4: Changes of the average hardness (in terms of 3 values) from the center to the surface of a hot-rolled billet of alloy PT-7M.

longitudinal and transverse cylindrical specimens. They were taken from the center, middle and periphery of the billet. The temperature of the experiment was $875^{\circ} \mathrm{C}$ and at a deformation rate of $12 \mathrm{~s}^{-1}$. The deformation temperature of $875^{\circ} \mathrm{C}$ is close to the lower limit of the recommended temperature range $\left(840-940{ }^{\circ} \mathrm{C}\right)$ for tube extrusion of near- $\alpha$ titanium OT4-1 alloy [5]. It has similar aluminum content (about $2 \%$ ) with PT-7M and $\mathrm{T}_{p t}\left(910-950^{\circ} \mathrm{C}\right)$. The test results are presented in Fig. 5.

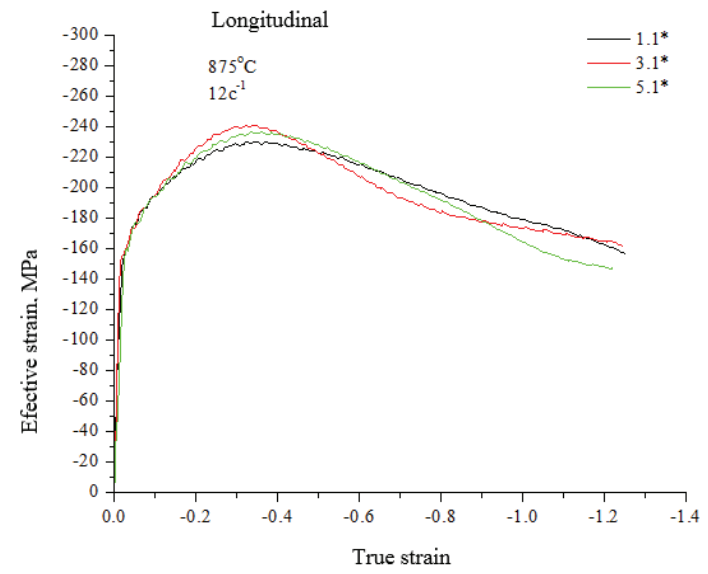

$a$

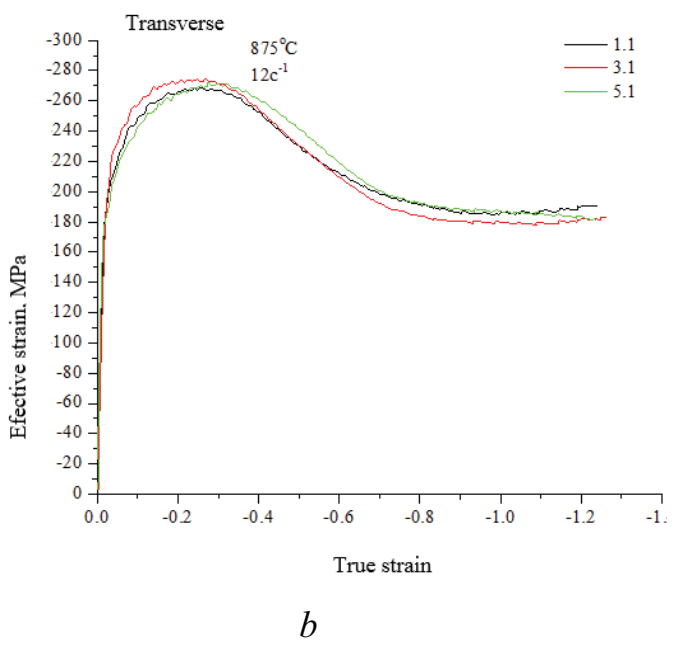

Figure 5: Curves of flow of metal samples from the center $\left(1.1^{*}, 1.1\right), 1 / 2$ of the radius $\left(3.1^{*}, 3.1\right)$ and at the surface $\left(5.1^{*}, 5.1\right)$ of the billet of alloy PT-7M: $a$ - longitudinal direction, $b$ - transverse direction.

The analysis of the curves and their comparison with the data of structural and hardness measurements (Fig. 1-4) allowed us to conclude the following. 
First, the smallest peak of effective strain during compression are typical for samples cut from the center of the billet in the longitudinal and transverse directions, because of the largest proportion of large macrograins (Fig. 1) and recrystallized grains (Fig. 2) and the lowest hardness accordingly (Fig. 4).

Secondly, the effective stresses for the similar true strain of specimens in the transverse direction are higher than in the longitudinal one with about 25-35 MPa (Fig. 5). It can be associated with the more favorable texture orientation of the crystallites in the longitudinal direction during compression as compared with the orientation of the crystallites in the transverse direction (Fig. 3).

Third, the deformation compression curves have a similar character. There is a flat maximum with true strain between 0.2-0.4 (Fig. 5). The similar type of strain curve was previously observed in $[5,12,13]$ and it is associated with two competing processes. The first one is hardening due to the generation of linear lattice defects (dislocations) during deformation, the second is softening due to the recovery and recrystallization processes of deformed alloy. The strain hardening predominates at a relatively small true strain (up to 0.3 ), but at higher values of true strain, the softening processes, primarily recrystallization, start to prevail. The possibility of the development of recrystallization processes in this alloy at a test temperature of $875^{\circ} \mathrm{C}$ is mentioned by the literature data [14]. Thus the temperature of the end of recrystallization of the alloy OT4-1, with aluminum content and $\mathrm{T}_{p t}$ close to PT-7M is $840^{\circ} \mathrm{C}$. In this case, it should be noted that the value of softening (the difference between the maximum value of the strain at the peak and the minimum value of the strain after the peak) is greater for samples cut from the surface compared to samples from the central part. We think that a smaller proportion of recrystallized in the center of the billet grains before testing compared to the surface could be the reason of this (Fig. 2). As a result, additional hot deformation during compression stimulates the development of recrystallization processes more actively in the samples near the surface of the billet which contributes to a greater softening.

\section{Conclusion}

The macro- and microstructure is characterized by a decrease in the volume fraction of large grains and a growth of the volume fraction of recrystallized grains from the center to the surface over the cross section of the large-sized billet of the PT-7M alloy. It contributes to the increase of hardness and true strain during hot compression tests at $875^{\circ} \mathrm{C}$. 
The study was supported by Russian Science Foundation, grant 18-79-10107.

\section{References}

[1] I.V. Gorynin, S.S. Ushkov, A.N. Khatuntsev, N.I. Loshakova, Titanium alloys for marine equipment. St. Petersburg, Politekhnika, 2007. 387p.

[2] A.A. Ilyin, B.A. Kolachev, I.S. Polkin. Titanium Alloys. Composition, Structure, Properties. Reference book. Moscow, VILS-MATI, 2009. 520 p.

[3] V.N. Moiseev, Titan in Russia. Physical metallurgy and heat treatment of metals, 2005, № 8, pp.23-29.

[4] S.S. Ushkov, A.S. Kudryashov, E.A. Karasev, Titanium alloys in shipbuilding and marine structures, Titan. 1 (2002). pp. 44-49.

[5] V.K. Aleksandrov, Semi-finished products from titanium alloys, M.: ONTI VILS 1996, $584 \mathrm{p}$.

[6] TU 1-5-132-78 Pipe blanks of titanium alloys. Technical conditions. Verhnyaya Salda, VSMPO. 1978. 9 p.

[7] GOST 19807-91 Wrought titanium and titanium alloys. Grades.. M.: Gosstandart. 1992. $32 \mathrm{p}$.

[8] S.G. Glazunov, B.A. Kolachev, Titanium alloys. Metallography of titanium alloys, M.: Metallurgy, 1980. 464 p.

[9] U. Zwicker Titan and its alloys, M.: Mir. 1979. 512 p. 